\title{
ENHANCEMENT OF SOLUBILITY AND DISSOLUTION RATE OF POORLY SOLUBLE IRBESARTAN BY POLYMORPHISM AND SOLID DISPERSION TECHNIQUES
}

\author{
T Amrutha Rai*, M Siva Prasanna, S Santosh Kumar, GSN Koteswara Rao, P Uma Devi \\ Department of Pharmaceutics, Viswanadha Institute of Pharmaceutical Sciences, \\ Mindivanipalem, Anandapuram, Visakhapatnam, A.P. \\ Corresponding Author e-mail: amu.kshatriya@gmail.com
}

Received: 30 April 2015

Revised: 20 May 2015

Accepted: 28 May 2015

\begin{abstract}
:
Solid dispersion refers to a group of solid products consisting of at least two different components, generally a hydrophilic matrix and a hydrophobic drug. The phenomenon of exisisting in more than one form is termed as polymorphism. In the present study, the selected drug Irbesartan exhibits polymorphism. Thus, lower the stability higher will be the solubility and dissolution rate of the polymorph. The drug was formulated as polymorph using various solvents. Among them, drug-ether polymorph has given highest solubility and dissolution rate. The formulation using ether as solvent and pregelatinized starch 1500 as carrier increased the solubility of Irbesartan using solid dispersion technique. The FTIR studies revealed that there is no indication of incompatibility between drug and excipients.
\end{abstract}

Key words: Solid dispersions, Irbesartan, Polymorph, FTIR.

\section{INTRODUCTION:}

Many potential drug candidates are characterized by a low oral bioavailability. Often poor drug dissolution/solubility rather than limited permeation through the epithelia of the gastrointestinal tract are responsible for low oral bioavailability. The rate and extent of dissolution of the active ingredient from any dosage form often determines the rate of extent of absorption of the drug. Therefore, a drug with poor aqueous solubility will typically exhibit dissolution rate limited absorption, and a drug with poor membrane permeability will typically exhibit permeation rate limited absorption [1] .Hence, two areas focus on improving the oral bioavailability of active agents include: (i) enhancing solubility and dissolution rate of poorly water-soluble drugs and (ii) enhancing permeability of poorly permeable drugs. Solid dispersion is one of the most promising approaches for solubility enhancement[2].

Irbesartan is an angiotensin receptor blocker (ARB) used mainly for the treatment of hypertension. It competes with angiotensin II for binding at the AT1 receptor subtype. It has an average absolute bioavailability of $60-80 \%$, volume of distribution - 53 to $93 \mathrm{~L}$, half-life of 11-15 hours and its structure is given in fig. 1.

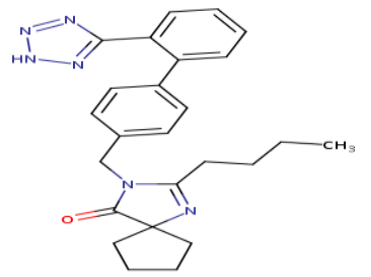

Fig. 1: Structure of Irbesartan

\section{How to cite this article:}

T Amrutha Rai et. al., Enhancement of solubility and dissolution rate of poorly soluble irbesartan by polymorphism and solid dispersion techniques. Int. J. Adv. Pharm. Biotech., 2015; 1(1): 54-59. 


\section{MATERIALS AND METHODS:}

Irbesartan (98.8\%) was obtained as a gift sample Aizant Drug Research Solutions Pvt. Ltd., Hyderabad. Ethanol, Acetone, Isopropyl alcohol (IPA), Chloroform, Ether, $0.1 \mathrm{~N} \mathrm{HCl}$, HPMC, HPMC K4M, HPMC K15M, HPMC K100M, Polyvinyl alcohol and Pregelatinized starch 1500 (PGS) were of analytical grade.

\section{Estimation of Irbesartan:}

$50 \mathrm{mg}$ of Irbesartan was dissolved in $10 \mathrm{ml}$ of methanol and the volume was adjusted up to $50 \mathrm{ml}$ with $0.1 \mathrm{~N}$ hydrochloric acid (Stock solution: $1000 \mu \mathrm{g} / \mathrm{ml}$ ). The main stock solution was diluted to $100 \mu \mathrm{g} / \mathrm{ml}$ in $0.1 \mathrm{~N} \mathrm{HCl}$. Then, the dilution was scanned in the UV region of $200-400 \mathrm{~nm}$ through U.V.
Spectrophotometer (Systronics). The maximum absorption was obtained at 210 $\mathrm{nm}$ and this wavelength was used for construction of standard graph by using different concentrations of the drug solution in $0.1 \mathrm{~N} \mathrm{HCl}$. The method obeyed Beer's law in the studied range of 1-10 $\mu \mathrm{g} / \mathrm{ml}$. In order to find the degree of linear relationship correlation coefficient (r) was calculated and the result was found to be 0.998.Next it was of interest to establish the mathematical form of linear relationship between the two variables (concentration and absorbance) under consideration and the equation obtained was: $\mathrm{y}=0.100 \mathrm{x}+$ 0.016 where $\mathrm{x}$ is the concentration of Irbesartan $(\mu \mathrm{g} / \mathrm{ml}), y$ is the absorbance. The calibration curve was shown in the fig. 2 .

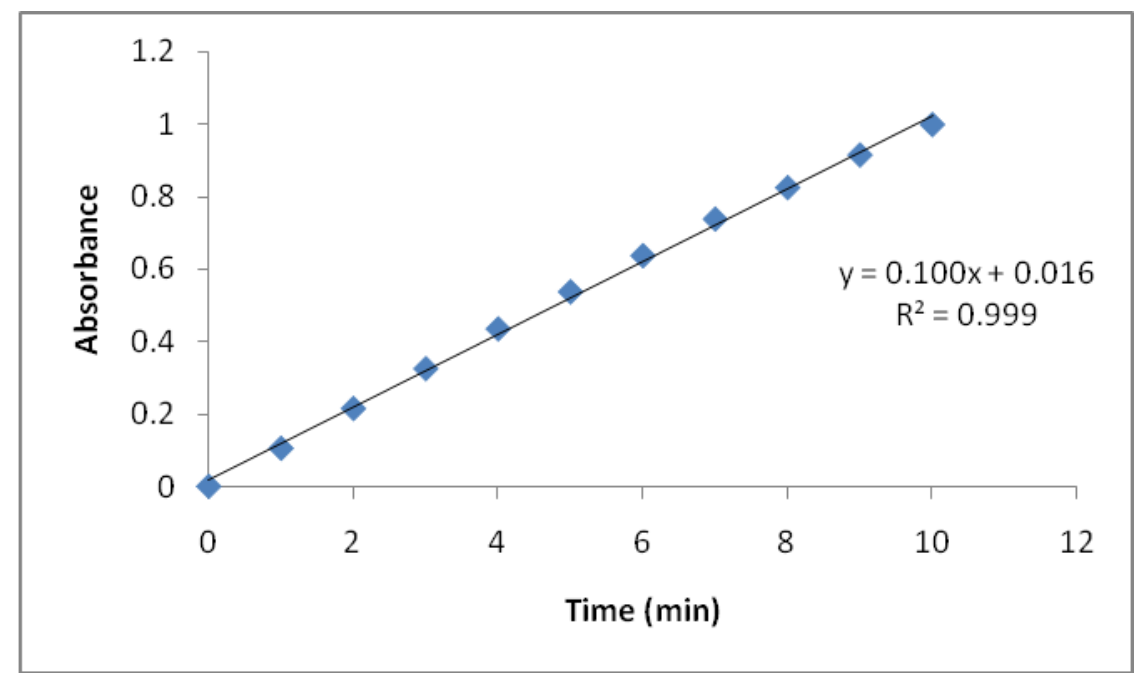

Fig. 2: Calibration curve of Irbesartan

\section{Preparation of drug polymorph:}

$50 \mathrm{mg}$ of Irbesartan of each was taken in 6 different china dishes. To each china dish containing drug, solvent (ether, ethanol, IPA, Chloroform, acetone and DCM) was added. The drug was dissolved by stirring with a glass rod. The solvent were evaporated by stirring with glass rod and stored in desiccators. The solvents used for preparation of polymorphs are ethanol, chloroform, acetone, ether, IPA. Capillary tubes selected for determination of melting point were filled with polymorphic forms at one end and inserted into melting point apparatus [3].The melting point of different drug polymorphs was observed and given in the table 1 . All the melting points are different. Thus, it indicates that the drug exhibits polymorphism. Then polymorphic forms were subjected to dissolution studies which exhibited different \% drug release rates as given in fig. 3 .

Table - 1: Melting point of drug polymorphs

\begin{tabular}{cc}
\hline Drug + solvent & Melting point range ( C) \\
\hline Irbesartan + Ethanol & $174-186$ \\
Irbesartan + Ether & $178-180$ \\
Irbesartan + DCM & $176-192$ \\
Irbesartan + IPA & $180-190$ \\
Irbesartan + Chloroform & $182-192$ \\
Irbesartan + Acetone & $182-188$ \\
\hline
\end{tabular}




\section{Preparation of solid dispersion:}

From the results given below, the drug ether polymorph has shown higher dissolution rate compared to other drugsolvent polymorphs. Thus, the drug - ether polymorph was selected for further enhancement of dissolution rate by employing solid dispersions technique. To the drug polymorph equal ratio of different polymers (drug: polymer (1:1)) were added and blended uniformly. The formula was given in the table 2. Different polymers used were, HPMC K4M, HPMC K15M, HPMC K100M, PVA, PGS 1500 and carboxy methyl ethyl cellulose (CMEC). The prepared solid dispersions were evaluated for drug release by conducting dissolution studies and percentage of drug release ${ }^{[4]}$ was given in fig. 4.

Table- 2: Formulation (in mg)

\begin{tabular}{lcccccc}
\hline \multicolumn{1}{c}{ Ingredient } & F1 & F2 & F3 & F4 & F5 & F6 \\
\hline Drug polymorph & 50 & 50 & 50 & 50 & 50 & 50 \\
PGS 1500 & 50 & - & - & - & - & - \\
PVA & - & 50 & - & - & - & - \\
HPMC K4M & - & - & 50 & - & - & - \\
HPMC K100LV+K4M & - & - & - & 50 & - & - \\
HPMC K15M & - & - & - & - & 50 & - \\
CMEC & - & - & - & - & - & 50 \\
\hline
\end{tabular}

\section{Dissolution study:}

The dissolution behavior of the drug polymorphs and the solid dispersions was evaluated using the following parameters: $900 \mathrm{ml}$ of $0.1 \mathrm{~N} \mathrm{HCl}$ at $37 \pm 0.5^{\circ} \mathrm{C}$ was used as dissolution medium. The USP apparatus type II; paddle method was used at $50 \mathrm{rpm}$. At definite time intervals $(5,10,15,30$ and $45 \mathrm{~min}$ ), $5 \mathrm{ml}$ of the dissolution fluid was withdrawn, filtered and subjected for spectrometric analysis at $210 \mathrm{~nm}$ after suitable dilutions as and when necessary[5]. Every time, $5 \mathrm{ml}$ of the fresh medium was replaced into the dissolution jar. Each experiment was carried out in triplicate. The results were given in fig. 3 and 4.

\section{Compatibility studies:}

Compatibility studies were conduct by using Fourier transform infrared spectroscopy (FTIR). FTIR spectra of Irbesartan, PGS 1500, drug-ether mixture and drug-PGS 1500 solid dispersion were shown in fig. 5-8. No significant alterations in the FTIR peak of the irbesartan, ether and PGS 1500 combination (fig. 6) were detected. Thus, there were no chemical interactions. The minor shift in the peaks associated with drug indicates some sort of solid state interactions between the drug and the polymer (in the solid dispersion and the physical mixture). The interactions may be due to the intermolecular hydrogen bonding between the drug and the polymer.

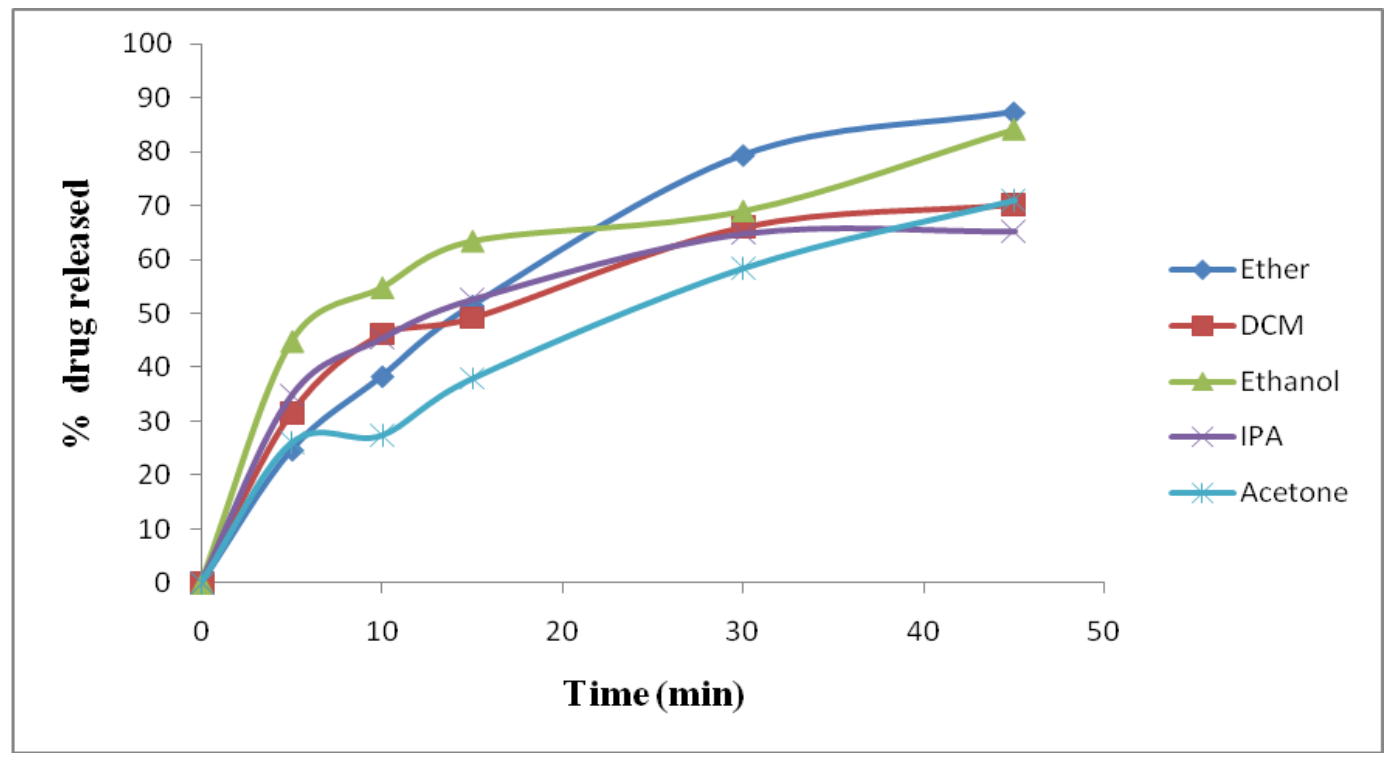

Fig. 3: Time vs. \% drug release plot of different drug polymorphs 


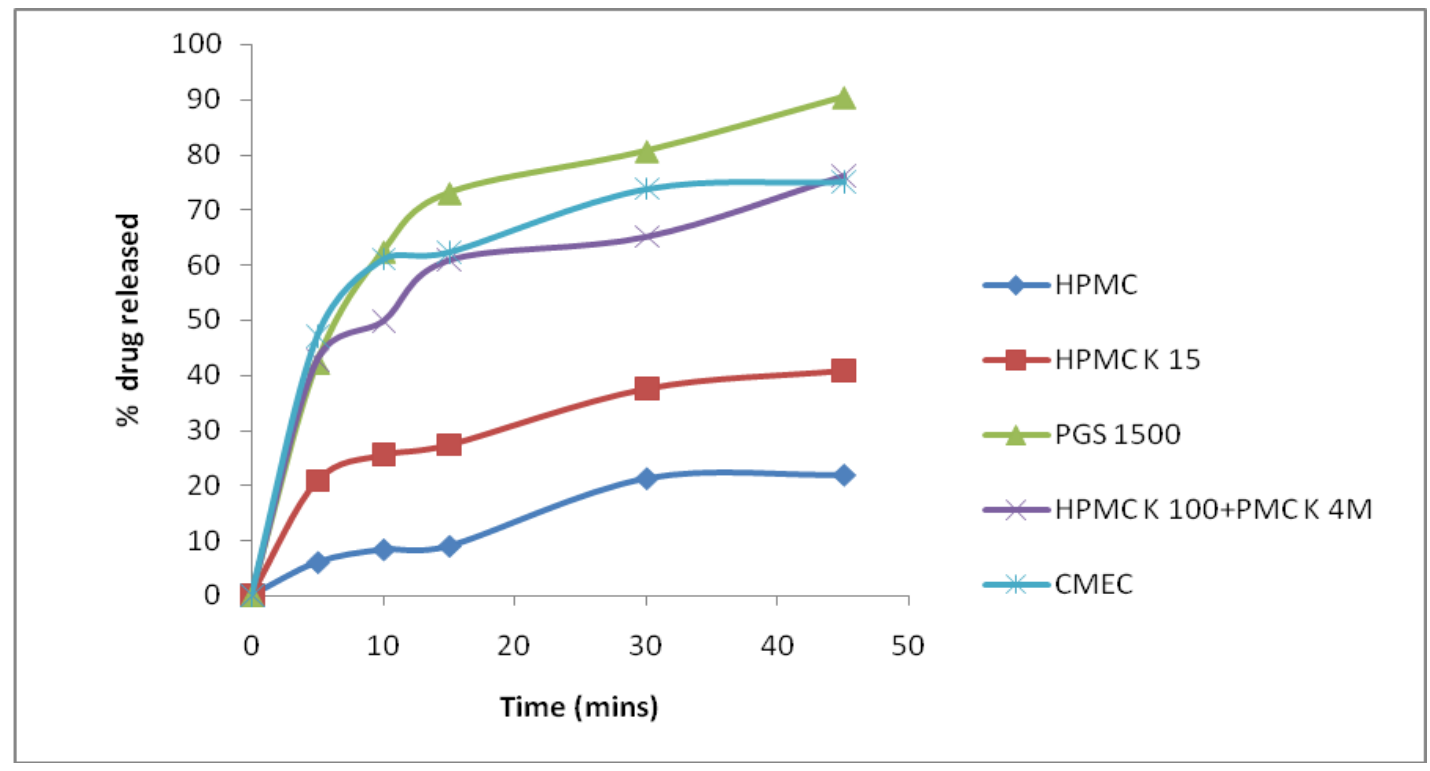

Fig. 4: Time vs. \% drug release plot of solid dispersions

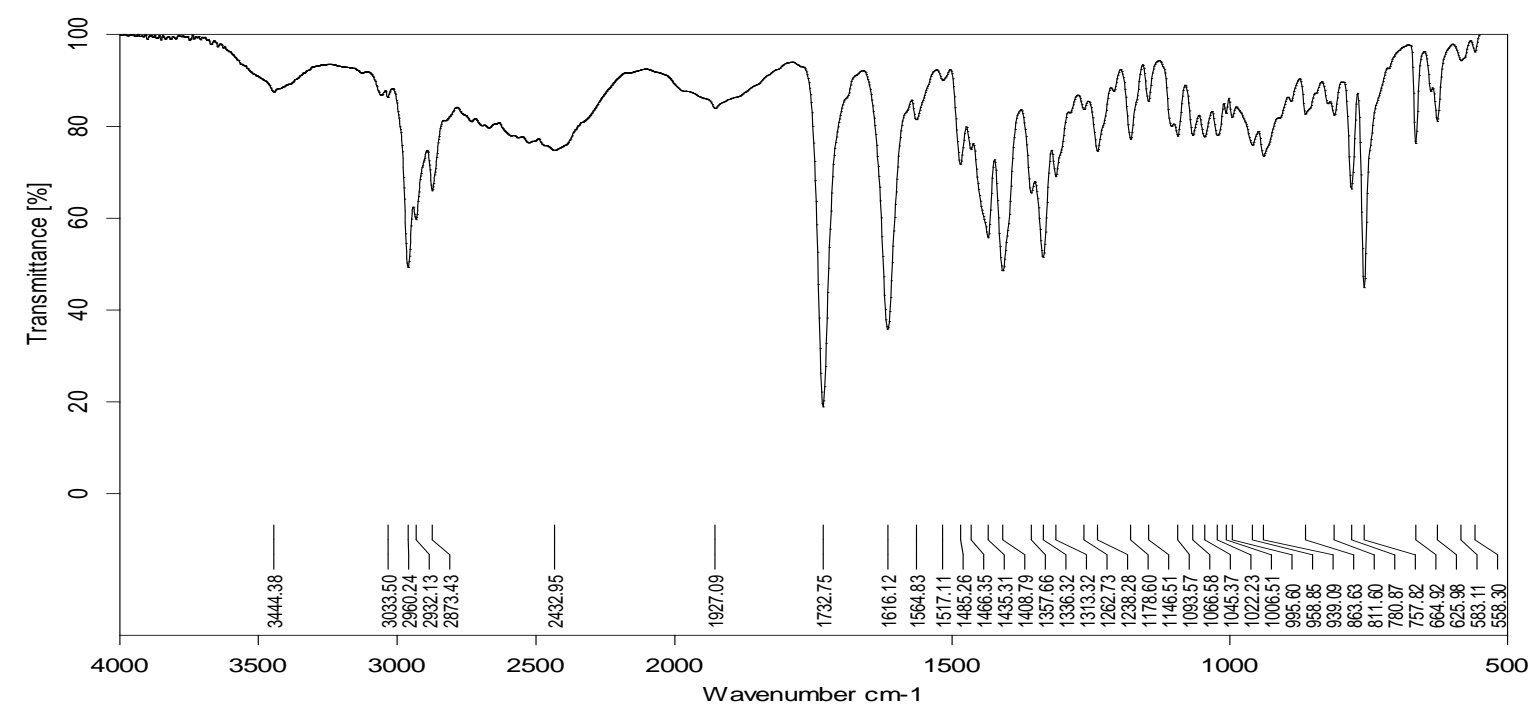

Fig. 5: FTIR spectra of Irbesartan

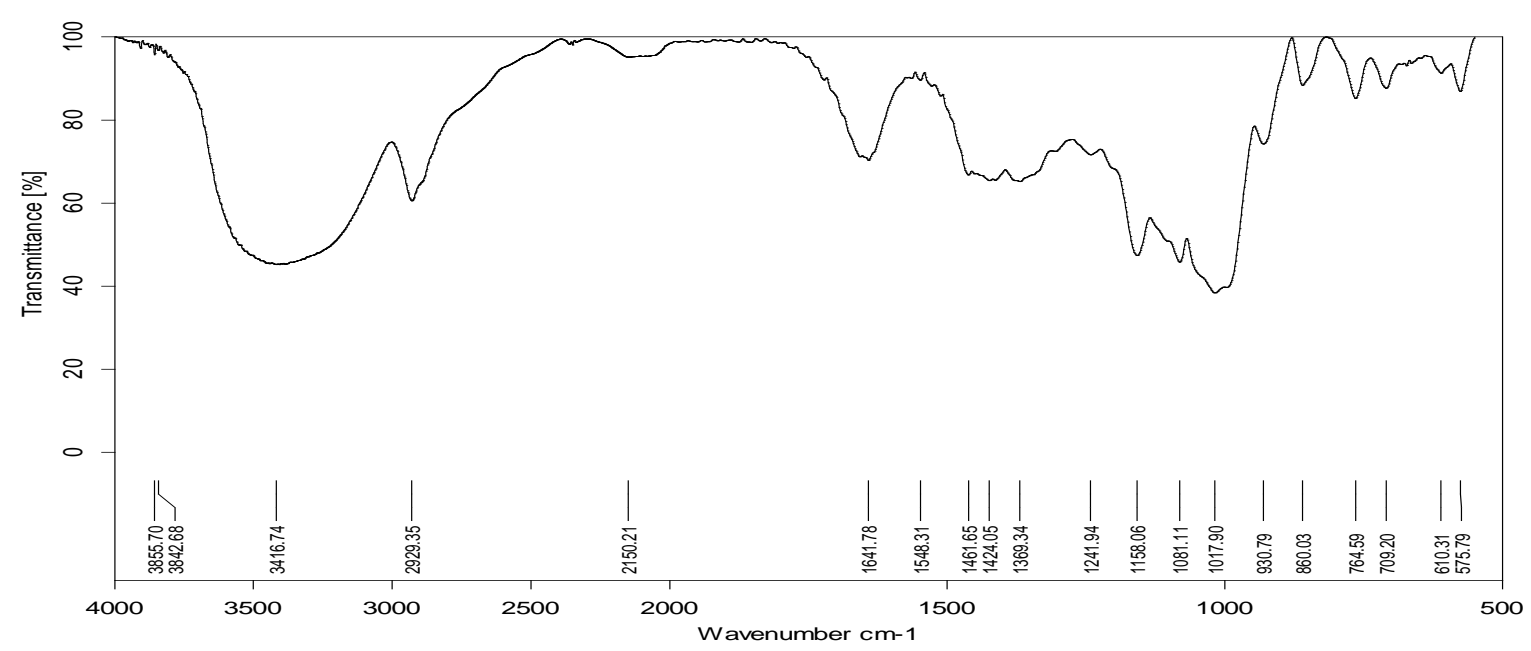

Fig. 6: FTIR spectra of PGS 1500 


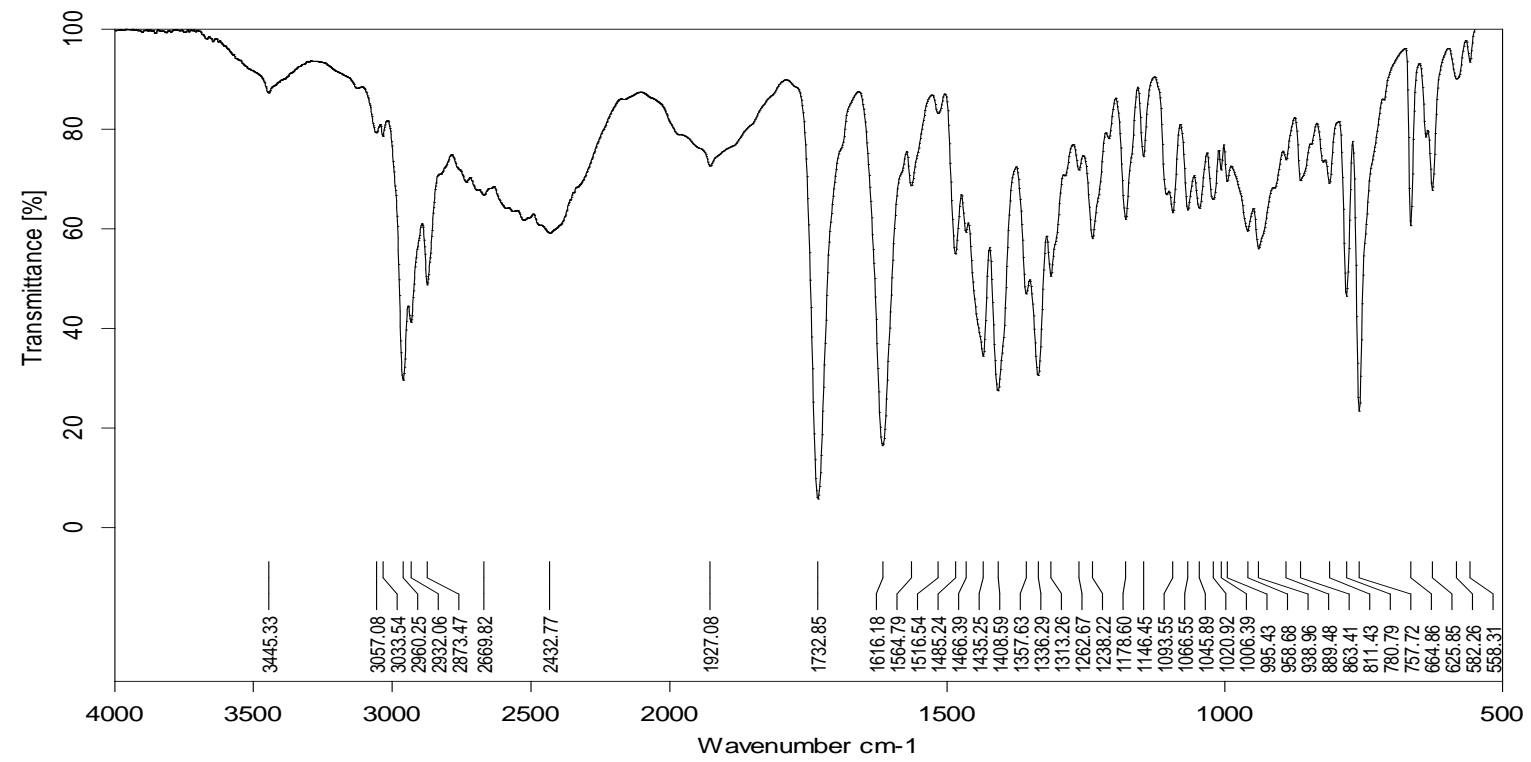

Fig.7: FTIR spectra of Irbesartan: Ether physical mixture

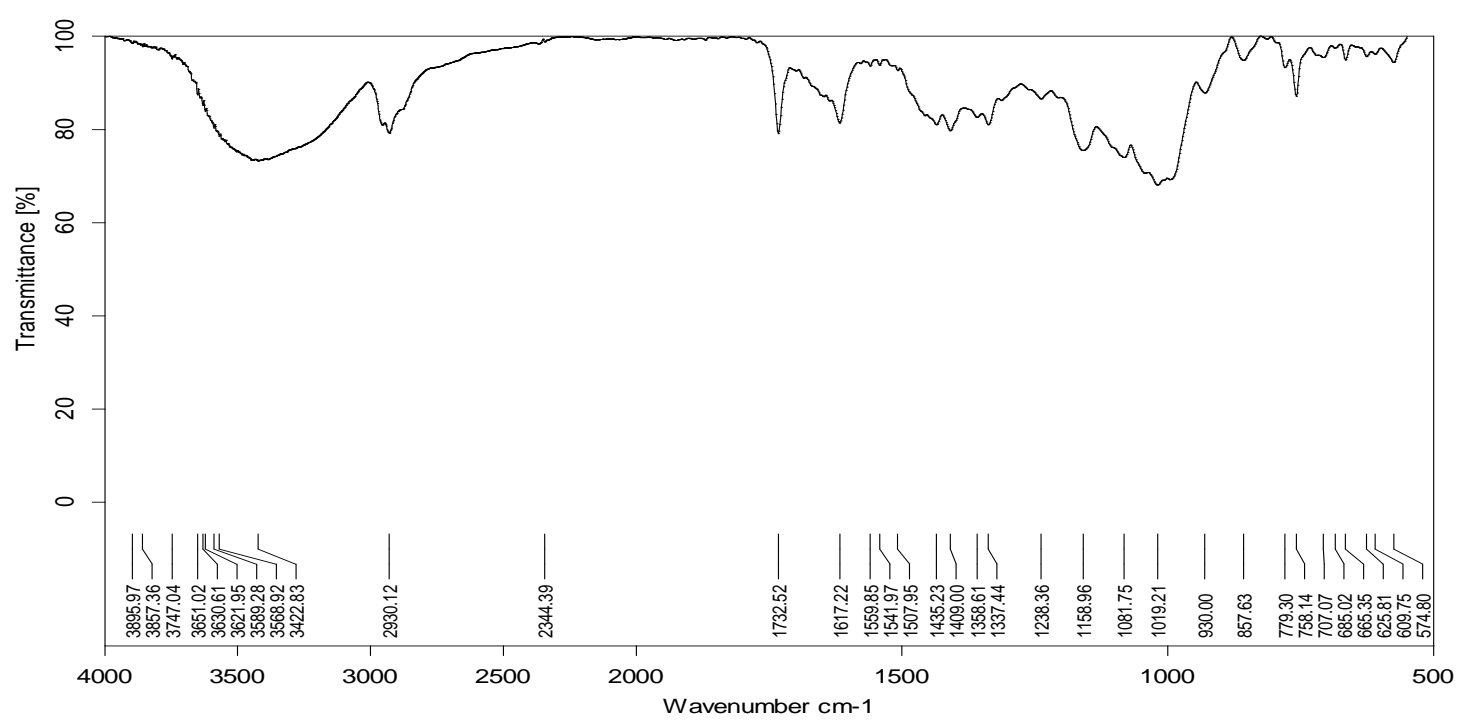

Fig. 8: FTIR spectra of Irbesartan: PGS 1500 physical mixture

\section{RESULTS \& DISCUSSION:}

The polymorph with ether showed lowest melting point $\left(178-180^{\circ} \mathrm{C}\right)$ which indicated that it was least stable polymorph. Chloroform polymorph showed highest melting point $\left(184-192^{\circ} \mathrm{C}\right)$. The dissolution study of polymorph with ether showed more drug release than other polymorphs which indicated that polymorph of ether was least stable. Thus, lower the melting point higher the solubility and dissolution. The drug-ether polymorph has shown highest dissolution rate compared to other polymorphs. Then, solid dispersions were formulated with different carriers by solvent evaporation method.

The formulation, F1 (drug ether polymorph: PGS 1500) further increased the solubility of Irbesartan using solid dispersion technique. The increase in dissolution rate can be assigned due to the reduced particle size of the drug deposited on carrier and enhanced wettability of the particles brought about by the carrier. Solubility and dissolution rate of Irbesartan was successfully enhanced by solid dispersion technique using pre - gelatinized starch as polymer along with drug ether polymorph. The FTIR spectral analysis revealed that there are no chemical interactions between the drug and other excipient used in the formulation.

\section{CONCLUSION:}

In the present study, solid dispersion method was employed to enhance the solubility and dissolution rate of Irbesartan. 
Irbesartan has undergone polymorphism by exhibiting different melting points with different solvents. The ether polymorph has shown less stability than others i.e., lower the melting point higher the solubility and dissolution rate. Then by employing solvent evaporation method, using different carriers dissolution studies were carried out. Among them F1 formulation has shown highest release resulting in increased dissolution rate of poorly soluble Irbesartan. FTIR studies have confirmed that there were no drugs - excipient interactions. Thus, solid dispersion technique can be successfully used for the enhancement of solubility and dissolution rate of poorly soluble hydrophobic drugs like Irbesartan.

\section{ACKNOWLEDGEMENT:}

The authors are thankful to Viswanadha Institute of Pharmaceutical Sciences for providing necessary facilities to carry out this research work.

\section{References:}

1. Dhirendra K, Lewis S, Udupa N, Atin K. Solid dispersions: a review. Pak. J. Pharm. Sci., 2009, 22(2): 234-246.

2. Naveen Dutt Dixit and Suneel Kumar Niranjan.A review: solid dispersion. World J. Pharm. Pharm. Sci., 2014, 3(9): 238-257.

3. Kaisar Raza, Pramod Kumar, Shanti Ratan, Ruchi Malik, Shweta Arora.
Polymorphism: the phenomenon affecting the performance of drugs. SOJ Pharm. Pharm. Sci., 2014, 1(3): 1-10.

4. Jahnavi N, Dixit A, Mehta A.K, Mohan Varma M. Formulation, evaluation and characterization of solid dispersions of pioglitazone hydrochloride. Indian J. Pharm. Edu. Res., 2013, 47(2): 113-12.

5. M. Santhosh Aruna, A. Kishore Babu, Madhurilatha Thadanki, M. Eswara Gupta. Solid dispersions - an approach to enhance the dissolution rate of irbesartan. Int. J. Res. Pharm. Chem., 2011,1(4): 780-787.

6. Mohammed Jafar, Dehghan MHG, Adil Shareef. Enhancement of dissolution and anti-inflammatory effect of meloxicam using solid dispersions. Int. J. Applied Pharm., 2010, 2(1): 22-27.

7. Santhosh Pola, Anand Kumar Meka, Hanumantha Rao K, Anand D, Shiva Prasad, C. Aparna. Development, evaluation and characterization of solid dispersion for solubility and Dissolution enhancement of irbesartan. Int. J. Res. Pharm. Chem., 2012, 2(2): 418-427.

8. G. Ashwini Kumar, Ram Kumar Choudhary, Ch. Chaitanya. Enhancement of solubility and dissolution rate of irbesartan by solid dispersion technique. Asian J. Pharm. Clin. Res., 2011, 4(2): 36-40. 